\title{
In vitro screening of unconventional feeds and various natural supplements for their ruminal methane mitigation potential when included in a maize-silage based diet
}

\author{
S.M. Staerfl, M. Kreuzer ${ }^{1}$ and C.R. Soliva \\ ETH Zurich, Institute of Plant, Animal and Agroecosystem Sciences \\ Universitaetstrasse 2, CH-8092 Zurich, Switzerland
}

(Received 12 July 2010; revised version 7 October 2010; accepted 26 November 2010)

\begin{abstract}
Various supplements and unconventional feeds (supplement-type: Acacia tannins, Yucca saponins, extruded linseed, lauric and myristic acid; medicinal-type plant parts: garlic bulbs, hop cones, grape seeds, maca hypocotyls; legumes: lupine seeds and lucerne meal) were screened with the in vitro Hohenheim gas test for their methane mitigating potential in an incubation period of $48 \mathrm{~h}$. The control diet consisted of maize silage and concentrate $(0.85: 0.15)$. Replacing $150 \mathrm{~g} / \mathrm{kg}$ dry matter of the control diet with garlic bulbs (Allium sativum) decreased methane by $50 \%$ and the methane-to-total gas ratio by 15 to $17 \%$ at 75 and $150 \mathrm{~g}$ garlic/kg DM. This was accompanied by a decline in acetate proportion of total short-chain fatty acids. Methane formation tended to be reduced by $15 \%$ with a high-tannin extract from Acacia mearnsii (50 g/kg diet). The methane-tototal gas ratio was not significantly affected by the other treatments. Accordingly, garlic turned out most promising for the mitigation of methane without negatively affecting rumen microbial fermentation.
\end{abstract}

KEY WORDS: rumen, fermentation, methane, garlic, tannin, supplement

\section{INTRODUCTION}

When mitigating methane $\left(\mathrm{CH}_{4}\right)$ in agriculture, especially from enteric fermentation in the ruminant, nutritional strategies are the primary target in

\footnotetext{
${ }^{1}$ Corresponding author: e-mail: michael.kreuzer@inw.agrl.ethz.ch
} 
identifying effective strategies (Martin et al., 2010). In order to be widely accepted, natural dietary ingredients are to be preferred. Such approaches are, however, often limited by a concomitantly impaired microbial nutrient fermentation. Therefore, the search for suitable $\mathrm{CH}_{4}$ inhibitors is still ongoing, and extensive screenings of promising plants have been undertaken, but this most often when added to grass, grass-silage and hay-based diets (e.g., Garcia-Gonzalez et al., 2008) or highconcentrate diets (Cardozo et al., 2005). Among the nutrients, lipids have turned out to be most effective in $\mathrm{CH}_{4}$ mitigation. Beauchemin et al. (2008) calculated from literature a reduction of enteric $\mathrm{CH}_{4}$ formation of $0.56 \%$ per $\mathrm{g}$ of lipid supplied per kg diet dry matter (DM). Especially medium-chain fatty acids (MCFA) such as lauric $\left(\mathrm{C}_{12}\right)$ and myristic $\left(\mathrm{C}_{14}\right)$ acid (Soliva et al., 2004a) and polyunsaturated fatty acids (PUFA) like linolenic acid (prevalent in linseed; Martin et al., 2008) were shown to be effective, but might also negatively influence feed intake and digestibility. Currently, the search for successful $\mathrm{CH}_{4}$ mitigating strategies focuses on plant secondary compounds (Garcia-Gonzalez et al., 2008). Many of the plants rich in these compounds grow best in the tropics. For example, the tannin extract from Acacia mearnsii was shown to significantly decrease $\mathrm{CH}_{4}$ emission in sheep and cows (Carulla et al., 2005; Grainger et al., 2009). As proposed by Tavendale et al. (2005), tannins may have a direct effect on methanogens and an indirect effect on hydrogen production due to a lower level of feed degradation. Some representatives of the group of saponins are classified as potential $\mathrm{CH}_{4}$ inhibitors as well (Martin et al., 2010). Their effect is often mediated by their anti-protozoal activity (Pen et al., 2006). A third group of interesting metabolites is represented by the essential oils which possess antimicrobial properties, and thus are capable to affect ruminal microbes (Martin et al., 2010). One example with demonstrated in vitro efficacy is garlic oil and its components, an effect probably exerted via an antimicrobial action of one or more of the sulphur containing compounds (e.g., Chaves et al., 2008). Entire garlic bulbs so far have only been researched with respect to their efficiency in mitigating $\mathrm{CH}_{4}$ when added to a rice straw-concentrate diet in vitro (Kongmun et al., 2010).

In the present study it was hypothesised that there is quite a list of plants rich in secondary metabolites which are effective in abating ruminal methane emission. The objective of the present in vitro study was, therefore, to screen a variety of unconventional feeds and natural supplements for their $\mathrm{CH}_{4}$ mitigating potential together with their effects on ruminal fermentation when added to diet based on maize silage, a major forage in ruminant meat and milk production, and not a grass- or grass-conserve based diet. The Hohenheim gas test was used as method suitable for comparing a large number of samples at the same time. Incubation was performed for $48 \mathrm{~h}$ instead of $24 \mathrm{~h}$ in order to cover effects on methane production also from slowly fermentable feed ingredients. The focus was put on feeds being 
rich in secondary compounds but which are not yet well investigated with respect to methanogenesis. These feeds included lucerne meal, garlic bulbs, grape seeds, hop cones, lupine seeds and maca hypocotyls. For comparative purpose, several supplements with already demonstrated efficacy were included as well. All feeds were tested in two different dosages which were either corresponding to levels presumed to be effective from the literature or equivalent to test feeds of a comparable nature.

\section{MATERIAL AND METHODS}

\section{Test substances and experimental design}

The test feeds were divided into three categories: feed supplements (i.e. supplied at relatively low levels), medicinal-type plant parts (i.e. substances which are in use for health purpose in humans or livestock or both) and selected grain or forage legumes. The supplements were added to a maize silage-based control diet (maize silage : soyabean meal : wheat, 0.85:0.08:0.07) which was incubated in an amount of $200 \mathrm{mg}$ dietary DM. The feed supplements (dosages in $\mathrm{g} / \mathrm{kg} \mathrm{DM}$ ) included an extract from a tropical tree bark rich in condensed tannins (25 and 50, Acacia mearnsii; Weibull black, TANAC S.A., Montenegro, Brazil), a saponincontaining extract (0.5 and 2.5; Yucca schidigera; MICRO-AID, Interferm AG, Zug, Switzerland), extruded linseed (50 and 100; via ExtruLin ${ }^{\circledR}$ 50b, Trinova AG, Wangen, Switzerland, consisting of a mixture of extruded linseed and wheat bran (as a carrier for the linseed oil) in a ratio of $1: 1$; equivalent to 25 and $50 \mathrm{~g}$ linseed/ $\mathrm{kg} \mathrm{DM}$; Linum usitatissimum), myristic acid $\left(50 ; \mathrm{C}_{14}\right)$ and a lauric and myristic acid mixture (50; $\mathrm{C}_{12}: \mathrm{C}_{14}, 1: 1$; Fluka Chemie GmbH, Buchs, Switzerland). The latter two were supplemented at a level of fat corresponding to twice of that supplied by the higher level of linseed. Different from the supplements, the medicinal-type plant parts and the legumes replaced distinct parts of the basal diet $(200 \mathrm{mg})$. The medicinal-type plant parts ( $\mathrm{g} / \mathrm{kg}$ dietary DM) involved hop (Humulus lupulus) cones (75 and 150), grape (Vitis vinifera) seeds (75 and 150), hypocotyls (below ground storage organs) of the high Andean plant maca (Lepidium meyenii) (75 and 150) and garlic (Allium sativum) bulbs (75 and 150). The legumes comprised lupine (Lupinus albus) seeds (150 and 300) and artificially dried lucerne (Medicago sativa) pellets (150 and 300). 


\section{Experimental and technical setup}

The Hohenheim syringe-based in vitro gas method by Menke and Steingass (1988), as described in detail by López et al. (2010), was used to carry out the short-term screening. Dry or dried feeds were used which all had been ground to pass a 1-mm sieve. Briefly, ruminal fluid was collected before morning feeding from a ruminally cannulated, lactating Brown Swiss cow fed hay ad libitum and concentrate $(0.5 \mathrm{~kg} / \mathrm{d})$. The cow was kept according to the Swiss guidelines of animal welfare. Ruminal fluid was filtered through four layers of medicinal gauze (type 17 MedPro, Novamed AG, Flawil, Switzerland) with a pore size of $1 \mathrm{~mm}$ to remove feed particles. All diets were incubated in six consecutive experimental runs ( $\mathrm{n}=6$ per treatment) in $30 \mathrm{ml}$ incubation liquid consisting of a mixture of filtered ruminal fluid and buffer solution 1:3; $/ \mathrm{v} ; 35 \mathrm{~g} / 1$ of $\mathrm{NaHCO}_{3}$ and $4 \mathrm{~g} / 1$ of $\left(\mathrm{NH}_{4} \mathrm{HCO}_{3}\right)$. Incubations at $39^{\circ} \mathrm{C}$ lasted for $48 \mathrm{~h}$. No syringes with blanks were incubated because results of total fermentation gas were reported as a difference to the not supplemented basal diet. At the end, total fermentation gas volume was determined from the calibrated scale printed on the incubation syringes. In fermentation gas, $\mathrm{CH}_{4}$ concentration was determined by gas chromatography (Hewlett Packard, model 5890 series II, Avondale, PA, USA). The gas samples had been obtained through a septum covering a second outlet of the Hohenheim syringes. Incubation liquid $\mathrm{pH}$ and ammonia concentration were determined using the respective electrodes connected to a potentiometer (model 713, Metrom, Herisau, Switzerland). For the analysis of the short chain fatty acids (SCFA), the samples were prepared following the method of Doane et al. (1998). Samples were then analysed using HPLC (LaChrom, L-7000 series, Hitachi Ltd., Tokyo, Japan) following Ehrlich et al. (1981).

The feed contents of DM, organic matter (OM) and N (C/N-Analyser, Typ FP2000, Leco Instrumente $\mathrm{GmbH}$, Kirchheim, Germany) were analysed following standard procedures (Naumann and Bassler, 1997). Crude protein (CP) was calculated as $6.25 \times \mathrm{N}$. Ash free neutral detergent fibre $(\mathrm{NDF})$ was analysed according to the protocol of Naumann and Bassler (1997) using $\alpha$-amylase (Termamyl 120L, Type S, Novo Nodirsk A/S, Bagsværd, Denmark). Gross energy (GE) was determined applying bomb calorimetry (Calorimeter C7000, IKAWerke GmbH \& Co. KG, Staufen, Germany). Ether extract (EE) was analysed using a Soxhlet extractor (Büchi Extraktionssystem B-811, Flawil, Switzerland). Contents of total phenols (TP) and total tannins (TT) were measured according to the Folin-Ciocalteu method (Makkar, 2003) where polyvinyl-polypyrrolidone is used to separate tannin phenols from non-tannin phenols. Different from the protocol of Makkar (2003), samples were initially boiled in aqueous acetone solution for $10 \mathrm{~min}$ to ensure that phenolic compounds were dissolved from the 
plant materials (Seigler et al., 1986). The results were given as equivalents of the tannic acid standard.

\section{Calculations and statistical analysis}

In vitro organic matter digestibility (IVOMD, \%) was calculated as: $14.88+0.8893 \times$ total gas $(\mathrm{ml})+0.0448 \times \mathrm{CP}(\mathrm{g} / \mathrm{kg} \mathrm{DM})+0.0651 \times$ ash $(\mathrm{g} / \mathrm{kg} \mathrm{DM})$

following Menke and Steingass (1988). Data was statistically analysed using the MIXED procedure of SAS 9.1 (SAS Institute Inc. Cary, NC). Model 1 included treatment and run as effects and was carried out separately across all treatments of each subgroup (supplements, medicinal-type plants, legumes) and the control. The experimental dosage regime allowed applying a second model for the medicinal plant parts and the legumes which considered, besides treatment and run, also the effect of the dosage and the interaction of the treatment $\times$ dosage. Model 2 did not include the control treatment. Treatment means were compared with the control and considered significant at $\mathrm{P}<0.05$.

\section{RESULTS}

The chemical composition of the test substances and the diets is shown in Table 1.

Supplementation of the basal diet with various substances mostly did not result in significant differences from control in either total fermentation gas and $\mathrm{CH}_{4}$ production or the $\mathrm{CH}_{4}$-to-fermentation gas ratio (Table 2). Fermentation gas and $\mathrm{CH}_{4}$ production, incubation liquid ammonia, and total SCFA concentration, in vitro organic matter digestibility (IVOMD), and $\mathrm{CH}_{4}$-to-GE-ratio were affected by treatment $(\mathrm{P}<0.05)$ and were particularly low with the higher level of CT though not significantly different from control. Incubation liquid $\mathrm{pH}$ and SCFA profiles were not affected $(\mathrm{P}>0.1)$ by any of the supplements.

Out of the diets containing medicinal-type plant parts in exchange of part of the control diet, garlic turned out to be most effective in affecting ruminal fermentation compared to the control (Table 3; control data displayed in Table $2)$. Especially the higher dosage of garlic decreased $(\mathrm{P}<0.05)$ the absolute level of $\mathrm{CH}_{4}$, the ratios of $\mathrm{CH}_{4}$-to-total gas, $\mathrm{CH}_{4}$-to- $\mathrm{GE}$ and $\mathrm{CH}_{4}$-to-SCFA as well as the acetate proportion of total SCFA compared to the control, while butyrate (and propionate) proportions were increased. The acetate-to-propionate ratio was low with garlic as well, but this was not significantly different from the control. Across all treatments there were clear $(\mathrm{P}<0.05)$ dosage effects in $\mathrm{CH}_{4}$-related variables and 
Table 1. Chemical composition (g/kg dry matter (DM)) and gross energy (MJ/kg DM) of the feeds

\begin{tabular}{|c|c|c|c|c|c|c|c|c|}
\hline Item & & $\mathrm{OM}^{1}$ & $\mathrm{CP}^{1}$ & $\mathrm{EE}^{1}$ & $\mathrm{NDF}^{1}$ & $\mathrm{TP}^{1}$ & $\mathrm{TT}^{1}$ & $\mathrm{GE}^{1}$ \\
\hline \multicolumn{9}{|l|}{ Ingredients } \\
\hline acacia tannin & & 969 & 34 & 1.6 & 7 & 717.0 & 695 & 20.8 \\
\hline yucca saponin & & 277 & 16 & 0.1 & 8 & 20.8 & 10.3 & 4.8 \\
\hline $\begin{array}{l}\text { linseed/wheat } \\
\text { bran mixture }\end{array}$ & & 947 & 192 & 29.2 & 527 & 8.5 & 3.6 & 22.0 \\
\hline $\mathrm{C}_{12}$ (lauric acid) & & 999 & - & 999 & - & - & - & 36.3 \\
\hline $\mathrm{C}_{14}$ (myristic acid) & & 999 & - & 999 & - & - & - & 35.9 \\
\hline hop cones & & 901 & 264 & 39.7 & 368 & 117.8 & 90.7 & 19.5 \\
\hline grape seeds & & 961 & 157 & 45.2 & 488 & 391.3 & 250 & 22.9 \\
\hline maca hypocotyls & & 949 & 136 & 9.5 & 87 & 31.1 & 14.1 & 17.6 \\
\hline garlic bulbs & & 959 & 221 & 4.9 & 31 & 5.2 & 0.5 & 17.8 \\
\hline lupine seeds & & 963 & 308 & 65.0 & 329 & 4.5 & - & 20.1 \\
\hline lucerne meal & & 877 & 170 & 19.0 & 322 & 37.4 & 19.0 & 18.1 \\
\hline maize silage & & 962 & 82 & 27.9 & 399 & 26.5 & 13.6 & 18.4 \\
\hline concentrate $^{2}$ & & 957 & 342 & 10.2 & 134 & 7.9 & 1.6 & 18.8 \\
\hline Total diets & Dosage $^{3}$ & & & & & & & \\
\hline control $^{4}$ & - & 961 & 121 & 25.3 & 360 & 23.7 & 11.8 & 18.4 \\
\hline \multirow[t]{2}{*}{ acacia tannin } & +25 & 961 & 118 & 24.4 & 347 & 48.3 & 36.0 & 18.5 \\
\hline & +50 & 961 & 115 & 23.6 & 335 & 71.5 & 58.9 & 18.6 \\
\hline \multirow[t]{2}{*}{ yucca saponin } & +0.5 & 959 & 121 & 25.2 & 358 & 23.7 & 11.8 & 18.4 \\
\hline & +2.5 & 952 & 120 & 24.9 & 355 & 23.7 & 11.8 & 18.3 \\
\hline \multirow{2}{*}{ linseed } & +50 & 960 & 127 & 25.6 & 373 & 22.4 & 11.1 & 18.7 \\
\hline & +100 & 959 & 132 & 25.9 & 385 & 21.3 & 10.5 & 18.9 \\
\hline & +50 & 963 & 115 & 70.8 & 343 & 22.6 & 11.2 & 19.3 \\
\hline $\mathrm{C}_{12}^{14} / \mathrm{C}_{14}(1: 1)$ & +50 & 963 & 115 & 70.8 & 343 & 22.6 & 11.2 & 19.3 \\
\hline \multirow[t]{2}{*}{ hop cones } & 75 & 957 & 148 & 26.4 & 362 & 30.8 & 17.7 & 18.5 \\
\hline & 150 & 952 & 141 & 27.5 & 362 & 37.9 & 23.7 & 18.6 \\
\hline \multirow[t]{2}{*}{ grape seeds } & 75 & 961 & 132 & 26.7 & 370 & 51.3 & 29.7 & 18.8 \\
\hline & 150 & 961 & 122 & 28.4 & 380 & 79.1 & 47.7 & 19.1 \\
\hline \multirow[t]{2}{*}{ maca hypocotyls } & 75 & 960 & 121 & 24.2 & 340 & 24.3 & 12.0 & 18.4 \\
\hline & 150 & 959 & 122 & 23.0 & 320 & 24.9 & 12.1 & 18.3 \\
\hline \multirow[t]{2}{*}{ garlic bulbs } & 75 & 961 & 127 & 23.9 & 337 & 22.4 & 11.0 & 18.4 \\
\hline & 150 & 961 & 135 & 22.3 & 312 & 21.0 & 10.2 & 18.3 \\
\hline \multirow[t]{2}{*}{ lupine seeds } & 150 & 961 & 148 & 31.2 & 356 & 20.9 & 10.1 & 18.7 \\
\hline & 300 & 962 & 175 & 37.1 & 352 & 18.1 & 8.3 & 18.9 \\
\hline \multirow[t]{2}{*}{ lucerne } & 150 & 949 & 127 & 24.4 & 355 & 25.8 & 12.9 & 18.4 \\
\hline & 300 & 936 & 135 & 23.4 & 349 & 27.7 & 13.9 & 18.3 \\
\hline
\end{tabular}

${ }^{1} \mathrm{OM}$ - organic matter; CP - crude protein; NDF - neutral detergent fibre; EE - ether extract; TP - total phenols; TT - total tannins (the latter two given as tannic acid equivalent); GE - gross energy; ${ }^{2}$ soyabean meal and wheat $\left(0.52: 0.48\right.$ on a DM basis) $;{ }^{3} \mathrm{~g} / \mathrm{kg}$ total dietary DM; ${ }^{4}$ maize silage and concentrate $(0.85: 0.15$ on a DM basis) 


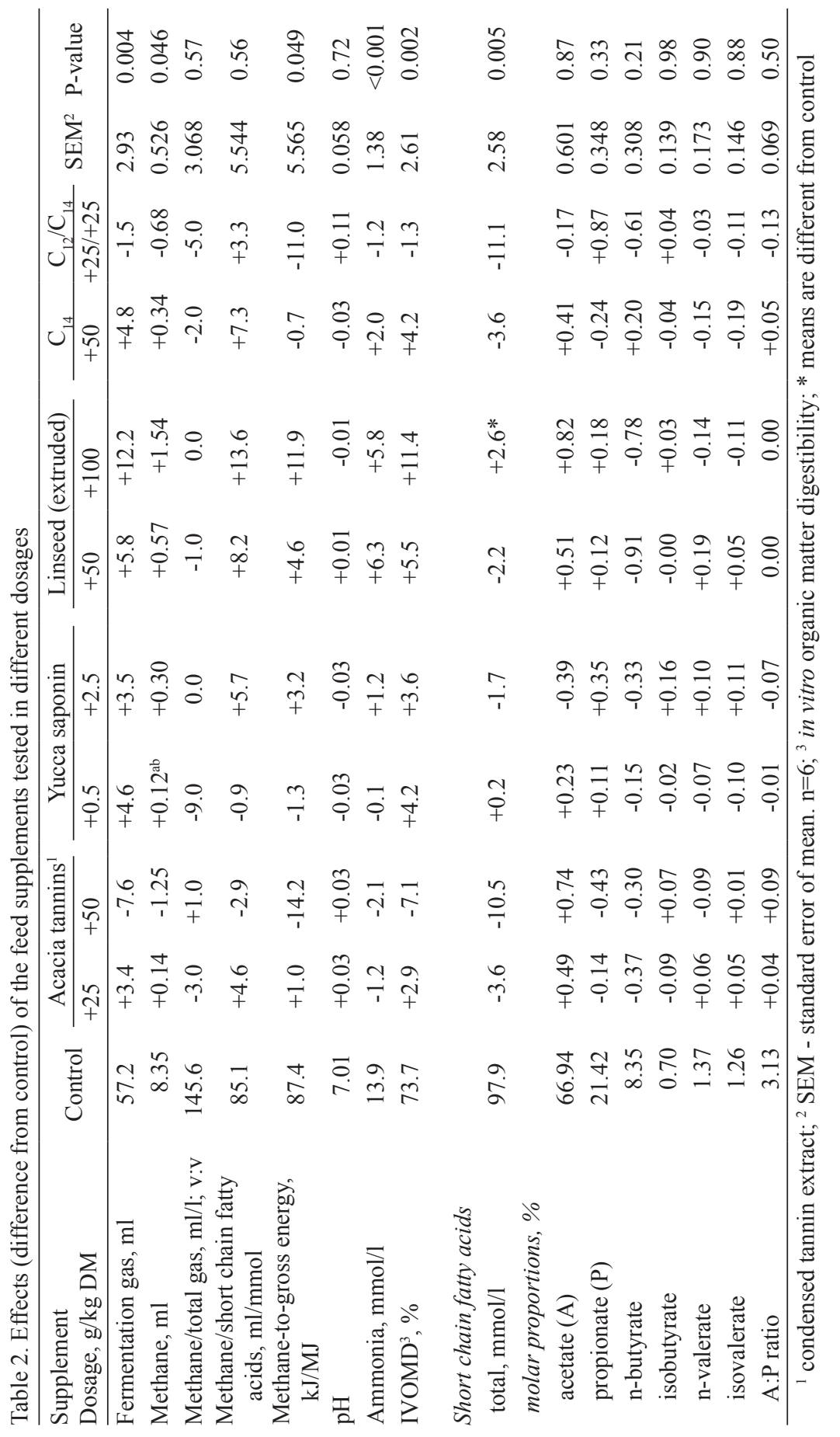




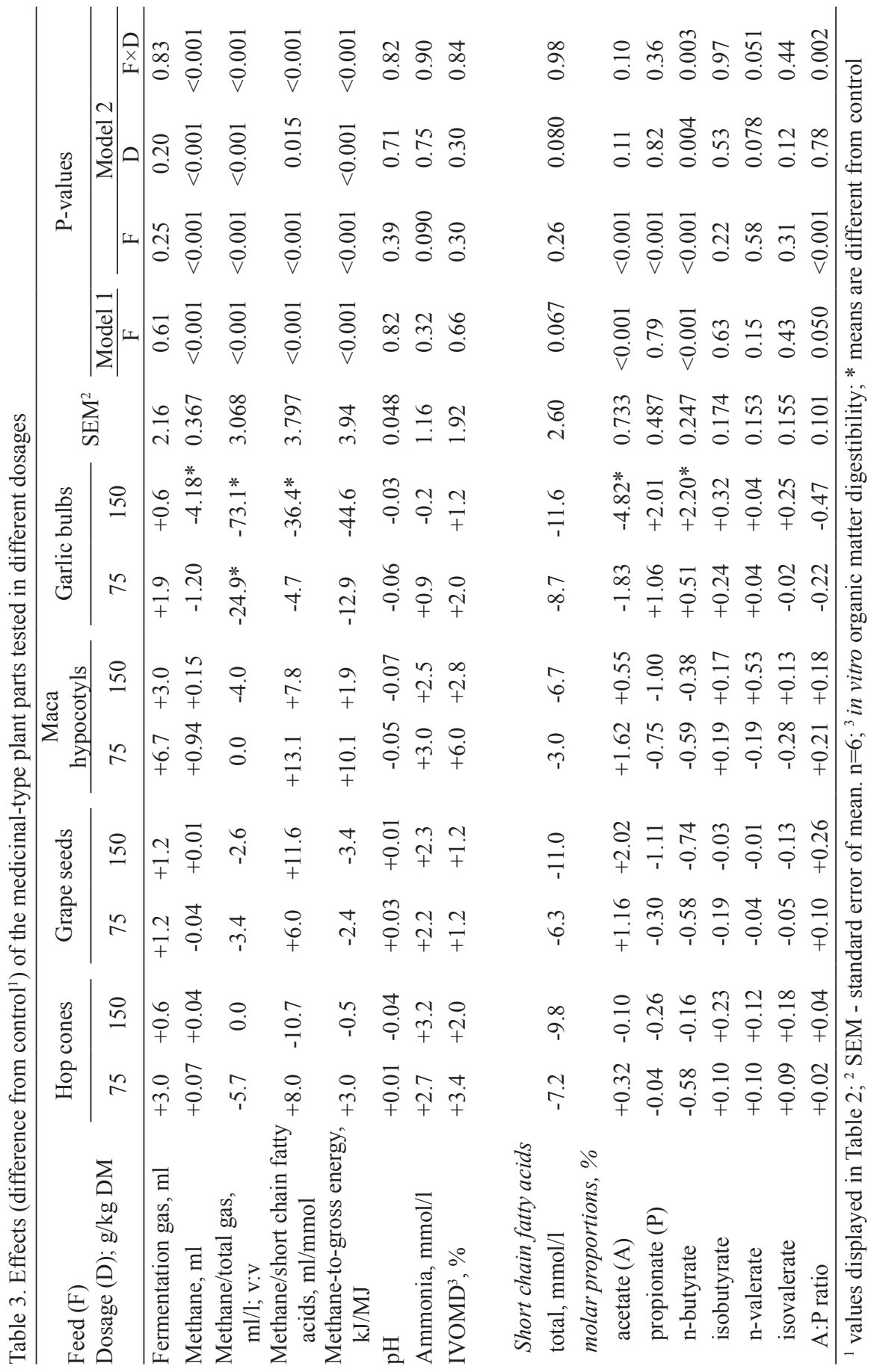




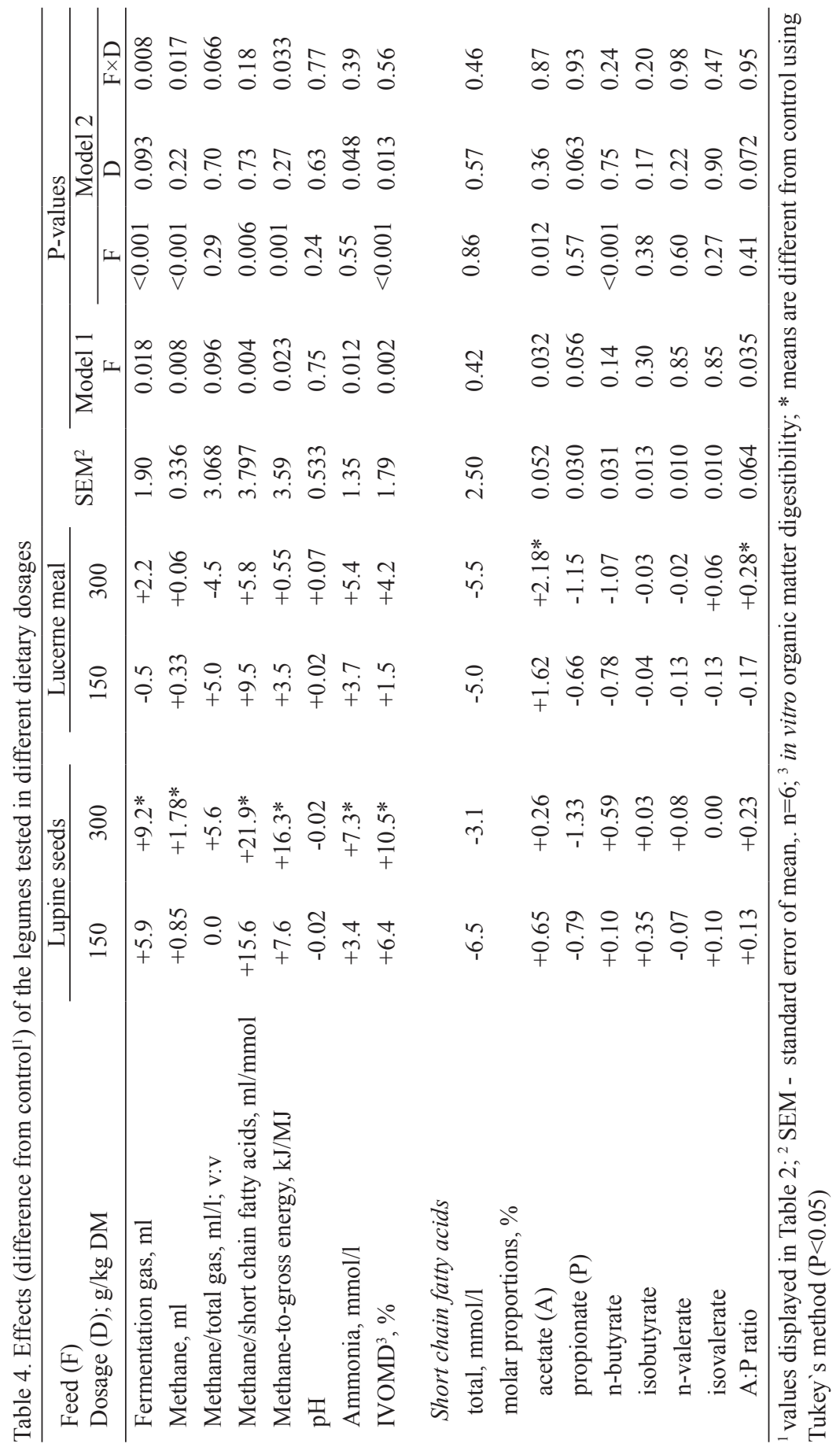


the proportions of the major SCFA which, however, mainly resulted from shifts taking place with garlic and less to those taking place with the other medicinal-type plant parts. The latter gets obvious from the significant feed $\times$ dosage interactions found for some variables. Fermentation gas production, incubation liquid $\mathrm{pH}$ and ammonia, IVOMD and total SCFA were not affected $(\mathrm{P}>0.1)$ by any of the medicinal plant parts.

In the group of the legumes selected, the higher level of lupine seeds resulted in a more intensive $(\mathrm{P}<0.05)$ fermentation, manifested in higher fermentation gas and $\mathrm{CH}_{4}$ production, incubation liquid ammonia, IVOMD and $\mathrm{CH}_{4}$-to-GE ratio compared to control (Table 4). Although the $\mathrm{CH}_{4}$-to-total gas ratio remained unaffected by the legumes tested, the $\mathrm{CH}_{4}$-to-SCFA ratio was elevated with the higher level of lupine seeds as well. The higher dosage of lucerne meal increased acetate proportion of total SCFA. The legumes did not affect $(\mathrm{P}>0.1)$ incubation liquid $\mathrm{pH}$. Effects $(\mathrm{P}<0.05)$ of dosage were rare. There were interactions between feed and dosage $(\mathrm{P}<0.05)$ in fermentation gas and $\mathrm{CH}_{4}$ volume resulting from the response to dosage with lupine seeds and the absence of such clear responses with lucerne meal.

\section{DISCUSSION}

Supplements. In the present study, where a maize-silage based diet had been used, none of the supplemented substances clearly decreased in vitro $\mathrm{CH}_{4}$ formation or affected the fermentation products compared to the non-supplemented diet. A maize-silage diet is expected to have a rather low methanogenic potential per se (Beauchemin et al., 2008). Still there were trends indicating a lower total $\mathrm{CH}_{4}$ formation of the tannins and a mixture of $\mathrm{C}_{12}$ and $\mathrm{C}_{14}$. This illustrates that with other dosages, or in the longer term, $\mathrm{CH}_{4}$ mitigation might be possible also in such a diet type. The possibly active compounds represented by the supplements included condensed tannins (CT), sarsaponin, one form of saponin, and fatty acids. Modes of action could be direct effects on methanogens (demonstrated especially for medium-chain fatty acids (MCFA); Soliva et al., 2004a,b), antiprotozoal effects (known to be exerted by saponins, MCFA and PUFA; Soliva et al., 2004b; Pen et al., 2006) or inhibiting organic matter (especially fibre) digestion followed by a lower $\mathrm{H}_{2}$ supply to the methanogens (Tavendale et al., 2005; known for CT, MCFA, PUFA). Experimental evidence for efficacy of acacia tannins was given by Carulla et al. (2005) feeding sheep grass-hay or grass-legume hay based diets and Grainger et al. (2009) in grazing dairy cows. Even at the higher dosage, supplementation of tannins did not significantly reduce $\mathrm{CH}_{4}$ production in the current study. Yucca schidigera sarsaponin proved to be effective only with very 
high dosages in vitro (Pen et al., 2006; up to $40 \mathrm{~g} / \mathrm{kg} \mathrm{DM}$ ). But it was ineffective in vivo in the study by Sliwiński et al. (2002) where rather low dosages had been supplemented $(\leq 0.1 \mathrm{~g} / \mathrm{kg} \mathrm{DM})$. This is consistent with results from the present experiment. Martin et al. (2008) found a decreased $\mathrm{CH}_{4}$ emission in cows fed 150 g extruded linseed $/ \mathrm{kg}$ DM to dairy cows. This could not be observed with any of the dosages ( 25 and $50 \mathrm{~g} / \mathrm{kg} \mathrm{DM}$ ) here. Various studies have shown that MCFA can be effective $\mathrm{CH}_{4}$ inhibitors and that there is an even higher efficiency of $\mathrm{C}_{12}$ and $\mathrm{C}_{14}$ mixtures (Soliva et al., 2004a,b). However, the use of a forage-based diet might explain the low efficiency of the MCFA found in the present study (Machmüller et al., 2003).

Medicinal-type plant parts. Out of the four medicinal-type plant parts screened, only garlic bulbs showed a clear $\mathrm{CH}_{4}$ mitigating effect compared to the control both in absolute terms and when related to total fermentation gas and SCFA (both indirect measures for the metabolizable energy content of the diet). Similar effects were also found in some other in vitro studies when supplementing garlic extracts (e.g., Cardozo et al., 2005; Chaves et al., 2008) and ground garlic bulbs (Kongmun et al., 2010). Chaves et al. (2008) added 100 and $250 \mathrm{mg} / \mathrm{l}$ of garlic oil to mixed ruminal microbes which decreased $\mathrm{CH}_{4}$ formation by about $70 \%$. The mode of action is not yet known. It might be based on an activity against fibre degradation as is suggested by the SCFA profile (lower acetate-propionateratio). Like in the present study, Cardozo et al. (2005) found a decrease in acetate proportion with garlic oil at unchanged propionate proportions but this was associated with a decrease in total SCFA concentration. According to Morvan et al. (1996) hydrogen could also be utilized to reduce sulphate to sulphides, which might be relevant as garlic is rich in sulphur containing compounds. Different from the present findings, the propionate proportion was decreased with an garlic extract at an unchanged acetate proportion in the study of Chaves et al. (2008).

Grape seed effects on ruminal methanogenesis are unknown. Spanghero et al. (2009) examined, besides others, the chemical composition and rumen fermentability of grape seeds in vitro. Compared with the other medicinal-type plant parts, grape seeds are characterized by high levels of total phenols and total tannins (Spanghero et al., 2009; present data) which might result in antimethanogenic effects. This was not the case in the present study and, despite the low feeding value, the grape seeds did not depress gas production and IVOMD although total SCFA concentration was rather low. Hop cones are feeds rich in specific plant secondary metabolites especially $\alpha$-acids like humulones and $\beta$-acids such as lupulones. Particularly the $\beta$-acids are known to have an antimicrobial effect (Wang et al., 2010). Nevertheless, in vitro ruminal fermentation (e.g., increased gas production and VFA) was affected by hop addition in the study of Wang et al. (2010). However, in the present study, hop cones neither affected 
fermentative activity nor incubation liquid ammonia nor $\mathrm{CH}_{4}$ formation.

Legumes. Legumes are characterized by different concentrations and types of tannins (cf. also the CT extract from Acacia mearnsii) and saponins (Waghorn et al., 2002), i.e. plant secondary metabolites which are potentially effective against methane formation. However, the results suggest that either concentrations were too low in the two feeds tested (likely for the lupine seeds) or they contained only ineffective compounds. Accordingly, lucerne meal remained neutral in gas production and fermentation variables and lupine seeds even promoted methanogenesis in relation to the energy content of the diet as the increase per unit of SCFA shows. It is nevertheless likely that this was a side-effect of a generally improved fermentation when supplementing the maize-silage dominated basal diet with a protein supplement like the lupine seeds. It was still unexpected that no increase in SCFA was found which had been reported by Rémond et al. (2003) when feeding about $200 \mathrm{~g}$ lupine seeds/kg DM to sheep.

The present screening with the Hohenheim Gas Test method had some limitations as well. For demonstrative purpose, rather high dosages of the tested substances had been chosen. These might be not fully feasible for practical purpose, but still the results indicated supplements worthwhile to be investigated in more detail. As the supplements were added at different proportions, the effect of the basal diet was also varied which might have limited the accuracy of treatment-caused changes for instance in the methane-to-SCFA-ratio. Finally, incubating diets for $48 \mathrm{~h}$ instead of $24 \mathrm{~h}$, performed to be able to fully consider also slowly degradable supplements, in turn might have led to a certain degradation of microbial cells before the end of incubation because the level of fermentable substrates was getting low.

\section{CONCLUSIONS}

The results of the present in vitro screening confirmed that garlic is highly effective in mitigating $\mathrm{CH}_{4}$ in vitro, also when added to a maize-silage based diet. The unexpectedly low efficiency of treatments found to be effective in other studies, especially tannin extract, linseed and the medium-chain fatty acids, could be due to the relatively low $\mathrm{CH}_{4}$-generating potential of this diet type (not apparent from the $\mathrm{CH}_{4}$-to-gross energy ratio which was rather high) compared to grass-, grass-silage or hay-based diets. This emphasises the importance to test promising feeds and supplements under various feeding conditions. Among the feeds lesswell researched in terms of antimethanogenic properties, hop cones, grape seeds, maca hypocotyls and lucerne meal were found less promising than garlic, and 
lupine seeds even promoted $\mathrm{CH}_{4}$. Garlic has to be tested in vivo in order to confirm its favourable effect and to determine any negative side-effects for instance on palatability of the feed and on off-flavours of animal source products. Practical issues such as limitations in current availability for animal nutrition and costefficiency of some of the tested substances have to be taken in consideration as well, but political demands for mitigation measures and economy-of-scale effects at high demand may rapidly change this situation.

\section{REFERENCES}

Beauchemin K., Kreuzer M., O’Mara F., McAllister T.A., 2008. Nutritional management for enteric methane abatement: a review. Aust. J. Exp. Agr. 48, 21-27

Cardozo P.W., Calsamiglia S., Ferret A., Kamel C., 2005. Screening of the effects of natural plant extracts at different $\mathrm{pH}$ on in vitro rumen microbial fermentation of a high concentrate diet for beef cattle. J. Anim. Sci. 83, 2572-2579

Carulla J.E., Kreuzer M., Machmüller A., Hess H.D., 2005. Supplementation of Acacia mearnsii tannins decreases methanogenesis and urinary nitrogen in forage-fed sheep. Aust. J. Agr. Res. 56, 961-970

Chaves A.V., He M.L., Yang W.Z., Hristov A.N., McAllister T.A., Benchaar C., 2008. Effects of essential oils on proteolytic, deaminative and methanogenic activities of missed ruminal bacteria. Can. J. Anim. Sci. 88, 117-122

Doane P.H., Pell A.N., Schofield P., 1998. Ensiling effects on the ethanol fractionation of forages using gas production. J. Anim. Sci. 76, 888-895

Ehrlich G.G., Goerlitz D.F., Bourell J.H., Eisen G.V., Godsy E.M., 1981. Liquid chromatographic procedure for fermentation product analysis in the identification of anaerobic bacteria. Appl. Environ. Microbiol. 42, 878-885

Garcia-Gonzalez R., Lopez S., Fernandez M., Bodas R., Gonzalez J.S., 2008. Screening the activity of plants and spices for decreasing ruminal methane production in vitro. Anim. Feed Sci. Tech. $147,36-52$

Grainger C., Clarke T., Auldist M.J., Beauchemin K.A., McGinn S.M., Waghorn G.C., Eckard R.J., 2009. Potential use of Acacia mearnsii condensed tannins to reduce methane emissions and nitrogen excretion from grazing dairy cows. Can. J. Anim. Sci. 89, 241-251

Kongmun P., Wanapat M., Pakdee P., Navanukraw C., 2010. Effect of coconut oil and garlic powder on in vitro fermentation using gas production technique. Livest. Sci. 127, 38-44

López S., Makkar H.P.S., Soliva C.R., 2010. Screening plants and plant products for methane inhibitors. In: P.E. Vercoe, H.P.S. Makkar, A.C. Schlink (Editors). In Vitro Screening of Plant Resources for Extra-Nutritional Attributes in Ruminants: Nuclear and Related Methodologies. Springer, Dordrecht (The Netherlands)

Machmüller A., Soliva C.R., Kreuzer M., 2003. Methane-suppressing effect of myristic acid in sheep as affected by dietary calcium and forage proportion. Brit. J. Nutr. 90, 529-540

Makkar H.P.S., 2003. Quantification of Tannins in Tree and Shrub Foliage: A Laboratory Manual. Kluwer Academic Publishers, Dordrecht (The Netherlands)

Martin C., Morgavi D.P., Doreau M., 2010. Methane mitigation in ruminants: from microbe to the farm scale. Animal 4, 351-365 
Martin C., Rouel J., Jouany J.P., Doreau M., Chilliard Y., 2008. Methane output and diet digestibility in response to feeding dairy cows crude linseed, extruded linseed, or linseed oil. J. Anim. Sci. $86,2642-2650$

Menke K.H., Steingass H., 1988. Estimation of the energetic feed value obtained from chemical analysis and in vitro gas production using rumen fluid. Anim. Res. Dev. 18, 7-55

Morvan B., Bonnemoy F., Fonty G., Gouet P., 1996. Quantitative determination of H2-utilizing acetogenic and sulfate-reducing bacteria and methanogenic Archaea from digestive tract of different mammals. Curr. Microbiol. 32, 129-133

Naumann C., Bassler R., 1997. Die chemische Untersuchung von Futtermitteln. Methodenbuch, Vol. 3. VDLUFA-Verlag, Darmstadt

Pen B., Sar C., Mwenya B., Kuwaki K., Morikawa R., Takahashi J., 2006. Effects of Yucca schidigera and Quillaja saponaria extracts on in vitro ruminal fermentation and methane emission. Anim. Feed Sci. Tech. 129, 175-186

Rémond D., Le Guen M.P., Poncet C., 2003. Degradation in the rumen and nutritional value of lupin (Lupinus albus L.) seed proteins effect of extrusion. Anim. Feed Sci. Tech. 105, 55-70

Seigler D.S., Seilheimer S., Keesy J., Huang H.F., 1986. Tannins from 4 common acacia species of Texas and Northeastern Mexico. Econ. Bot. 40, 220-232

Sliwiński B.J., Kreuzer M., Wettstein H.-R., Machmüller A., 2002. Rumen fermentation and nitrogen balance of lambs fed diets containing plant extracts rich in tannins and saponins, and associated emissions of nitrogen and methane. Arch. Anim. Nutr. 56, 379-392

Soliva C.R., Meile L., Cieslak A., Kreuzer M., Machmüller A., 2004a. Rumen simulation technique study on the interactions of dietary lauric and myristic acid supplementation in suppressing ruminal methanogenesis. Brit. J. Nutr. 92, 689-700

Soliva C.R., Meile L., Hindrichsen I.K., Kreuzer M., Machmüller A., 2004b. Myristic acid supports the immediate inhibitory effect of lauric acid on ruminal methanogens and methane release. Anaerobe 10, 269-276

Spanghero M., Salem A.Z.M., Robinson P.H., 2009. Chemical composition, including secondary metabolites, and rumen fermentability of seeds and pulp of Californian (USA) and Italian grape pomaces. Anim. Feed Sci. Tech. 152, 243-255

Tavendale M.H., Meagher L.P., Pacheco D., Walker N., Attwood G.T., Sivakumaran S., 2005. Methane production from in vitro rumen incubations with Lotus pedunculatus and Medicago sativa, and effects of extractable condensed tannin fractions on methanogenesis. Anim. Feed Sci. Tech. 123, 403-419

Waghorn G.C., Tavendale M.H., Woodfield D.R., 2002. Methanogenesis from forages fed to sheep. Proc. N.Z. Grassl. Assn. 65, 167-171

Wang Y., Chaves A.V., Rigby F.L., He M.L., McAllister T.A., 2010. Effects of hops on ruminal fermentation, growth, carcass traits and shedding of Escherichia coli of feedlot cattle. Livest. Sci. $129,135-140$ 